has been made to the necessity of moistening the cornea during operation, and thinks that the keratitis mentioned on page 262 may be due to the omission of this very necessary precaution in tropical work. ' I should be very sorry to give the impression that I do not value the moistening of the cornea. I am wholly in agreement with him on the subject, and it has always been the custom in Madras to use an irrigator very freely for this and other purposes.

I have broken my rule of never answering reviews, driven by the fear that the impression conveyed to so able a critic as Colonel Herbert might be shared by others of less experience, and so lead some beginners to omit a measure on whose necessity I am absolutely in agreement with my reviewer.

\title{
Yours truly,
}

Oct. 31st.

R. H. Elliot, Lt.-Col. I.M.S., Retired.

\section{MODIFIED ANGELUCCI'S FIXATION}

To the Editor of the BRITISH JOURNAE OF OPHTHALMOLOGY.

DEAR SIR,-I have now adopted , as a routine measure, a modification of Angelucci's method of fixation in cataract and other intra-ocular operations. I pass a silk suture through the superior rectus tendon, and bring the two ends separated on to the forehead, where an assistant fixes them with his fingers; the lid is thus held firmly out of the way while the eye is rotated downwards, it is impossible for any pressure to be put on the eyeball, the suture can be released instantaneously without the manipulation necessary with a speculum, which can be dispensed with, and while fixation forceps can be used for the section in cataract, they are unnecessary afterwards.

lansdowne Place, Hove,

Yours faithfully,

October 17, 1920.

W. H. BRAILEY.

\section{BOOK NOIICE}

Clinical Ophthalmology for the General Practitioner. By A. MAITLAND RAMSAY, M.D., with foreword by Sir JAMES MacKenZIE, M.D., F.R.S. London: Hepry Frowde, Oxford University Press, and Hodder \& Stoughton. 1920. Price 42s. net.

In undertaking to write a book on "Clinical Ophthalmology for the General Practitioner," the author set himself a novel task and jone not free from difficulty. Whether or no his attempt has been successful, i.e., whether he has given the man in general practice 
what he wants, must be determined by practitioners themselves. With a negligible experience of general practice we feel that our judgment on this question is valueless. We do, however, feel competent to express an opinion on the intrinsic merits of the book, an opinion entirely favourable to it, and congratulatory to the author.

The book is well written, well illustrated and well printed, and undoubtedly fills a gap in ophthalmological literature.

We have read it with interest and pleasure, and although we have to justify the position of reviewer by some criticism, we heartily commend the book to the general practitioner and others interested in ophthalmology.

The volume contains 500 pages, of which the text occupies 410 pages: the remainder is devoted to therapeutic notes and formulae (61 pp.), a glossary of ophthalmological terms and derivations, and an index.

It is admittedly difficult, when writing on a special subject, for those who are not, and do not intend to be, specialists therein, to know when to stop; the author's aim, as set forth in the preface " has been to indicate, as far as possible, the cases which the general practitioner can treat safely on his own responsibility, and those in which it is desirable to obtain a consultation with an expert." It seems scarcely in accord with this aim to give detailed instructions for the performance of operations, e.g., for cataract, and for intraocular foreign bodies, which few general practitioners would care to undertake. Those, however, who desire to operate, or are compelled to do so, will obtain all the help that written descriptions can afford from the author's clear and decisive words of advice.

The arrangement of the contents seems to us excellent. The first and second chapters on "The Methodical Examination of the Eye," and "Important Symptoms in Diseases of the Eye," will furnish the reader, even one quitè alien to ophthalmology, with a knowledge of first principles which should prove very helpful in further study and in the examination of cases. The subsequent fortythree chapters all reach so high a standard that criticism is disarmed. One (chapter 36) which, though not clinical, will prove of great practical assistance ${ }^{2}$ to many medical men, is that on "Eye Injuries with Special Reference to the Workmen's Compensation Act, 1906."

The big things of this book are so good that it would be paltry to find fault with details, and we, therefore, pass by certain minor matters concerning which we are not wholly in agreement. We envy the author his obviously robust faith in the efficacy of drugs.

The illuminations consist of twenty full page plates, eleven of which are in colours. Most of the plates contain three to six figures. With few exceptions they are very good, and, we think, have been well selected for the readers whom the book is designed to serve. 
Plate 18 , in our view, might have been made more intelligible to the inexperienced if the false images had been connected by a dotted line with that part of the retina of the deviating eye from which they are projected. The illustration of iris bombé (plate 10, fig. 1) is not at all realistic.

The Oxford University Press have taught us to expect something approaching perfection in regard to printing and freedom from typographical errors in books issued by them. This work sustains their reputation. Of the very few mistakes noted, attention may be directed to two. Crede's name is anglicized so that by the uninitiated it will be pronounced as Creed, and the synonym of choked disc is given as "Stauung's papilla."

Sir James MacKenzie's foreword is full of rugged common sense, and we wish that it might be read by all those who propose to become the authors of books on medical subjects.

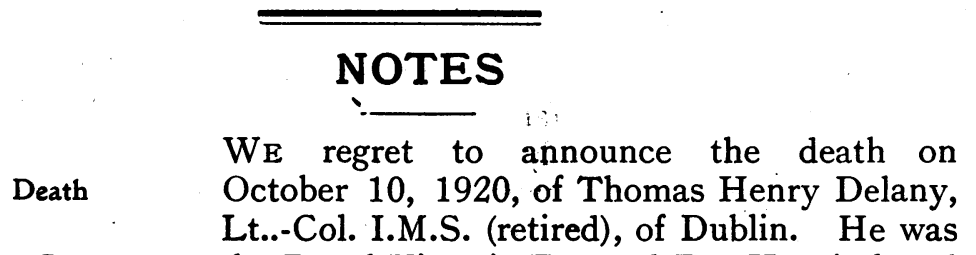
Assistant Surgeon to the Royal Victoria Eye and Ear Hospital, and Hon. Secretary and Treasurer of the Irish Ophthalmological Society.

DR. A. H. H. SinclaIR has been appointed an Appointments ophthalmic surgeon and Dr. E. H. Cameron Edinburgh Royal Infirmary.

an assistant ophthalmic surgeon to the

AT a meeting held on October 20, Dr. Elections George MacKay was re-elected President of the Royal College of Surgeons of Edinburgh. Dr. Freeland Fergus has been re-elected President of the Royal Faculty of Physicians and Surgeons , of Glasgow. Mr. R. H. Dickson, of Newcastle, Staffs., has been elected President of the North Staffordshire Medical Society.

LACK of space precluded our mentioning in Royal Society of Medicine the last number more than the names of the President and Secretaries for 1920-21 of the Section of Ophthalmology of the Royal Society of Medicine. The list is completed below: Vice-Presidents-E. Treacher Collins, William Lang, A. Maitland Ramsay, J. B. Story, E. E. Maddox, Sir Arnold Lawson, K.B.E., W.T. Holmes Spicer. Other Members 